\title{
Early effects of hypothyroidism on the contractile function of the rat heart and its tolerance to hypothermic ischemia
}

We have investigated the early effects of hypothyroidism on cardiac function and tolerance to hypothermic ischemia. Hypothyroidism was induced by thyroidectomy. Five days after operation, shamoperated and thyroidectomized rats were anesthetized and cardiac function was assessed. At this time, the plasma levels of triiodothyronine and thyroxine had fallen by eightfold and threefold, respectively, in thyroidectomized rats compared with the values in sham-operated rats. In vivo pump function was assessed by measuring mean arterial pressure, cardiac index, and stroke volume index: all were reduced by thyroidectomy (respectively $95 \pm 5 \mathrm{~mm} \mathrm{Hg}, 22 \pm 2 \mathrm{ml} / \mathrm{min} / 100 \mathrm{gm}$ body weight, and $67 \pm 7$ $\mu \mathrm{l} /$ beat $/ 100 \mathrm{gm}$ body weight versus $112 \pm 4 \mathrm{~mm} \mathrm{Hg}, 35 \pm 1 \mathrm{ml} / \mathrm{min} / 100 \mathrm{gm}$ body weight and $85 \pm 4 \mu \mathrm{l} /$ beat $/ 100 \mathrm{gm}$ body weight in the sham-operated group; $p<0.05$ in each instance). Systemic vascular resistance index was higher in thyroidectomized than in sham-operated rats $(4.4 \pm 0.4$ versus $3.1 \pm 0.2 \mathrm{~mm} \mathrm{Hg} / \mathrm{ml} / \mathrm{min} / 100 \mathrm{gm}$ body weight; $p<0.05$ ). In vivo indices of contractile function were also reduced by thyroidectomy: maximum rate of left ventricular pressure development fell by almost $50 \%(5190 \pm 790$ versus $9600 \pm 900 \mathrm{~mm} \mathrm{Hg} / \mathrm{sec} ; p<0.05)$ and left ventricular developed pressure and heart rate also fell (respectively $92 \pm 8 \mathrm{~mm} \mathrm{Hg}$ and 340 beats/min versus $129 \pm 6 \mathrm{~mm} \mathrm{Hg}$ and $398 \pm 6$ beats/min; $p<0.05$ in each instance). After excision, hearts were blood-perfused and ex vivo function assessed with intraventricular balloons. Systolic and diastolic functions were significantly impaired in the thyroidectomized group and the myocardial $\mathrm{Na}^{+}-\mathrm{K}^{+}$-adenosinetriphosphatase activity was reduced from a control value of $8.3 \pm 0.3$ to $5.8 \pm 0.4$ mean integrated extinction $\times 100$. The hearts were then subjected to 2 minutes of cardioplegic infusion, 6 hours of hypothermic $\left(4^{\circ} \mathrm{C}\right)$ ischemia, and $\mathbf{4 0}$ minutes of reperfusion. In control hearts, left ventricular developed pressure (at an end-diastolic pressure of $8 \mathrm{~mm} \mathrm{Hg}$ ) recovered to $76 \%$ of its preischemic value $(131 \pm 8$ versus $173 \pm 8 \mathrm{~mm} \mathrm{Hg} ; p<0.05$; in hearts from thyroidectomized rats, left ventricular developed pressure recovered to $81 \%$ of its preischemic value $(110 \pm 8$ versus $136 \pm 12 \mathrm{~mm} \mathrm{Hg} ; p=$ not significant), an absolute value that was not significantly different from that in the sham-operated group. Diastolic function recovered to the same extent in both groups. Myocardial high-energy phosphate content was unaffected by thyroidectomy and was depleted to a similar extent in both sham-operated and thyroidectomized groups by hypothermic ischemia. In conclusion, thyroidectomy leads to a deterioration of systolic and diastolic functions but this does not adversely affect the tolerance of the heart to extended periods of hypothermic ischemic storage. (J THORAC CARDIOvaSC SURG 1994;107:829-37)

Manuel Galiñanes, MD, PhD, Ryszard T. Smolenski, MD, Peter S. Haddock, PhD, and David J. Hearse, PhD, DSc, London, United Kingdom

From Cardiovascular Research, The Rayne Institute, St. Thomas' Hospital, London, United Kingdom.

Supported in part by grants from STRUTH.

Received for publication June 17, 1993.

Accepted for publication Aug. 27, 1993.

Address for reprints: Manuel Galiñanes, MD, PhD, Cardiovascular

Research, The Rayne Institute, St. Thomas' Hospital, London SE1 7EH, United Kingdom.

Copyright $(1994$ by Mosby-Year Book, Inc.

$0022-5223 / 94 \$ 3.00+0 \quad 12 / 1 / 51200$
Although controversial, ${ }^{1,2}$ there is evidence that thy-
roid function is frequently altered in brain-dead
patients. ${ }^{3-6}$ If this is the case, an insufficiency of circulat-
ing thyroid hormones might contribute to the cardiac
dysfunction often seen after brain death and this, in turn,
might impair the tolerance of the heart to the extended
periods of hypothermic ischemic storage that are often
necessary before cardiac transplantation. ${ }^{3-7}$
Thyroid hormones have marked effects on the growth, 
development, and metabolic function of virtually all organs and tissues ${ }^{8}$; thyroid status is also an important determinant of cardiovascular function. ${ }^{9-11}$ Alterations in cardiovascular function associated with changes in the thyroid status have been interpreted as secondary to the changes in peripheral vascular resistance, ${ }^{9}$ metabolic demand, ${ }^{10}$ and contractile characteristics ${ }^{11}$ induced by the hypothyroid state. These observations probably explain why more than $50 \%$ of surgical groups administer thyroid hormones in an attempt to improve the hemodynamic status of organ donors and the outcome of transplantation. ${ }^{12}$

Although changes in myocardial contractility have been observed in experimental hypothyroidism when the deficit has been present for more than 2 weeks, ${ }^{11,13-17}$ it is not known whether a shorter deficiency (as often applies in the context of brain-dead patients who are considered as potential organ donors) has any effect on cardiac function. We and others have reported that brain death is followed by a rapid deterioration of cardiac function ${ }^{6,7,18}$; however, our study also demonstrated that this loss of function could be fully reversed by explanation and ex vivo perfusion of the heart. Our studies have also revealed that brain death does not adversely influence the tolerance of the heart to long periods of hypothermic ischemic storage $^{18}$; however, these experiments were done soon (1 hour) after the induction of brain death, that is, at a time when the effect of any endocrine alteration might not yet be evident. The objectives of the present study (done in the rat) were therefore to investigate the early effects (5 days) of hypothyroidism on (1) in vivo and in vitro cardiac function and (2) the tolerance of the heart to hypothermic ischemic storage.

\section{Materials and methods}

Animals. Male Wistar rats ( 300 to $350 \mathrm{gm}$ ), having been thyroidectomized (or sham-operated) by the supplier (Charles River, Kent, United Kingdom), were housed in individual cages at $21^{\circ} \pm 1^{\circ} \mathrm{C}$, a relative humidity of $55 \% \pm 5 \%$, and with lights on from 7:00 AM to 9:00 PM. They remained in an unrestrained state and received tap water and chow ad libitum. Because the parathyroid glands can be damaged during the removal of the thyroid gland, calcium lactate $(1.5 \% \mathrm{wt} / \mathrm{vol})$ was added to the drinking water of all animals to avoid the tetanic convulsions that may appear as a consequence of the loss of control over calcium homeostasis. All animals received humane care in compliance with the "Principles of Laboratory Animal Care" formulated by the National Society for Medical Research and the "Guide for the Care and Use of Laboratory Animals" prepared by the National Academy of Sciences and published by the National Institutes of Health (NIH Publication No. 86-23, revised 1985).

Plasma levels of thyroid hormones. Blood samples obtained from both sham-operated and thyroidectomized animals $(n=15$ per group) were anticoagulated with heparin, centri- fuged, and the plasma aspirated and stored at $-170^{\circ} \mathrm{C}$ in liquid nitrogen until assay.

Total triiodothyronine and thyroxine levels were measured by a radioimmunoassay procedure based on the principles described by Ekins ${ }^{19}$ and modified for rat serum. The reference standards were made up in hormone-depleted rat serum and the assays done at an alkaline $\mathrm{pH}(8.2)$. The assay mixture contained 8-amidino-1-naphthalene sulfonic acid to liberate bound hormones from the binding proteins. Series of quality-control samples were included in the assays to monitor possible assay drift.

Surgical procedures and experimental protocol

Invivo assessment of cardiac pump function. Five days after operation, sham-operated and thyroidectomized rats $(n=8$ per group) were anesthetized with pentobarbital $(60 \mathrm{mg} / \mathrm{kg}$, intraperitoneally) and the lungs mechanically ventilated (via a tracheostomy) at a rate of 55 strokes/min and a ventilation pressure of 12 to $14 \mathrm{~mm} \mathrm{Hg}$. A femoral artery and vein were cannulated for recording arterial pressure and for the intravenous administration of heparin $(1000 \mathrm{IU} / \mathrm{kg})$. A microthermistor probe was positioned in the aortic arch (through the left common carotid artery) for monitoring temperature. A cannula (Abbocath-T 22G; Abbott Critical Care Systems, Salt Lake City, Utah), introduced into the right atrium through the right external jugular vein, was used for recording the right atrial pressure (RAP) and also for the injection of cold $\left(4^{\circ} \mathrm{C}\right)$ saline $(100 \mu \mathrm{l})$ for the assessment of cardiac output $(\mathrm{CO})$ by a thermodilution computer (Hoyer Medizintechnik $\mathrm{GmbH}$, Bremin, Germany). Heart rate (HR) and mean arterial pressure (MAP) were also recorded. Cardiac index (CI), stroke volume index (SVI), and systemic vascular resistance index (SVRI) were calculated from the cardiac output and heart rate according to the following formulas: $\mathrm{CI}=(\mathrm{CO} \times 100) / \mathrm{gm}$ body weight; $\mathrm{SVI}=(\mathrm{CI} / \mathrm{HR}) \times 1000$; and $\mathrm{SVRI}=(\mathrm{MAP}-$ $\mathrm{RAP}) / \mathrm{CI}$.

In vivo assessment of cardiac contractile function. Again, 5 days after operation, sham-operated and thyroidectomized rats ( $n=8$ per group) were anesthetized, the lungs ventilated, and cannulas placed as before. A polyethylene cannula $(1 \mathrm{~mm}$ external diameter) was introduced into the left ventricle through the right carotid artery. Left ventricular developed pressure (LVDP), maximum rate of isovolumic left ventricular pressure development $\left(\mathrm{LV} \mathrm{dP} / \mathrm{dt}_{\max }\right)$, left ventricular end-diastolic pressure (LVEDP), and heart rate were then recorded.

In vitro assessment of cardiac contractile function. After the in vivo assessment of cardiac function, hearts ( $n=8$ each group) from sham-operated and thyroidectomized rats were excised and perfused with blood from a support rat (see following sections) for the ex vivo assessment of cardiac function. After 40 minutes of perfusion in the Langendorff ${ }^{20}$ mode, a balloon catheter, attached to a pressure transducer, was inserted into the left ventricle through the left atrium. The balloon was progressively inflated to achieve stepwise increases of $\operatorname{LVEDP}(4,8,12$, 16 , and $20 \mathrm{~mm} \mathrm{Hg}$ ), and LVDP was measured. Heart rate was maintained at 320 beats $/ \mathrm{min}$ by right atrial pacing. Hearts were then freeze-clamped and taken for metabolite analysis.

Preservation of the heart during hypothermic cardioplegic arrest. After the in vivo assessment of cardiac function, the chest was opened and the heart excised and placed in cold $\left(4^{\circ} \mathrm{C}\right)$ saline. The aorta was rapidly cannulated and a cardioplegic solution (containing, in millimoles per liter, $\mathrm{NaCl} 130.0, \mathrm{KCl}$ $16.0, \mathrm{MgCl}_{2} 16.0, \mathrm{CaCl}_{2} 1.2$, and $\mathrm{NaHCO}_{3} 10.0$ at pH 7.8) was immediately infused at a constant pressure $(45 \mathrm{~mm} \mathrm{Hg}$ ) for 2 minutes at $4^{\circ} \mathrm{C}$. The hearts ( $n=8$ per group) were stored, 
immersed in the same cardioplegic solution, for 6 hours at $4^{\circ} \mathrm{C}$. They were then reperfused with blood as described later.

Ex vivo assessment of the recovery of cardiac function. A support rat was anesthetized with pentobarbital $(60 \mathrm{mg} / \mathrm{kg}$, intraperitoneally) and placed supine on a heated pad $\left(37^{\circ} \pm 0.5^{\circ} \mathrm{C}\right)$. The animal was allowed to breathe spontaneously a mixture of $95 \% \mathrm{O}_{2}$ and $5 \% \mathrm{CO}_{2}$, the flow of which was controlled so as to maintain arterial $\mathrm{O}_{2}$ tension and $\mathrm{CO}_{2}$ tension within the physiologic range. Heparin $(1000 \mathrm{IU} / \mathrm{kg}$, intravenously) was administered and a femoral artery and vein were cannulated for the supply of arterial blood at $37^{\circ} \mathrm{C}$ to the perfused heart and the return of venous blood to the support animal through a blood filter (porosity $200 \mu \mathrm{m}$ ).

The stored hearts were reperfused for 40 minutes in the Langendorff ${ }^{20}$ mode with arterial blood from the support rat delivered via a calibrated peristaltic pump. Perfusion pressure was monitored continuously and maintained at $60 \mathrm{~mm} \mathrm{Hg}$. The temperature of the blood was maintained at $37.0^{\circ} \mathrm{C}$ by a thermostatically regulated heat exchange system. Hearts were also paced at 320 beats $/ \mathrm{min}$, and at the end of reperfusion cardiac function was assessed as indicated earlier. The hearts were then freeze-clamped and taken for metabolite analysis.

Metabolite analysis. The frozen hearts were lyophilized and 30 to $40 \mathrm{mg}$ of the dried tissue was weighed and extracted with perchloric acid $(0.6 \mathrm{~mol} / \mathrm{L}, 25 \mu \mathrm{l} / \mathrm{mg}$ dry tissue $)$. The extract was centrifuged $\left(11,000 \mathrm{~g}\right.$ for 5 minutes at $\left.4^{\circ} \mathrm{C}\right)$ before removal of the supernatant and neutralization with potassium hydroxide $(2 \mathrm{~mol} / \mathrm{L})$. Aliquots $(20 \mu \mathrm{l})$ were taken for analysis by highperformance liquid chromatography. The method for chromatographic analysis of nucleotides and catabolites has been described in detail elsewhere. ${ }^{21}$ Briefly, the chromatographic system consisted of a Merck-Hitachi liquid chromatograph (Hitachi Medical Systems America, Inc., Hudson, Ohio) equipped with a Li-Chrograph 6200 pump, L-4250 programmable detector, and AS-2000 autosampler. Sample peaks were integrated and quantified with a D-2500 chromatographic integrator. The analytic column $(150 \times 4.6 \mathrm{~mm}$ internal diameter $)$ was packed with $3 \mu \mathrm{m}$ ODS Hypersil media. Chromatographic conditions were as follows: buffer A was potassium dihydrogen orthophosphate $150 \mathrm{mmol} / \mathrm{L}$ solution containing potassium chloride (150 mmol/L, pH 6.0); buffer B was a $15 \%(\mathrm{vol} / \mathrm{vol})$ solution of acetonitrile in buffer $A$ and its content in the mobile phase changed from $0 \%$ to $100 \%$ along the gradient curve as described. ${ }^{21}$ The values obtained were used to calculate the following indices of myocardial energy status: (1) total adenylate pool $=[\mathrm{ATP}+\mathrm{ADP}+\mathrm{AMP}]$ and (2) adenylate energy charge $=[0.5 \mathrm{ADP}+\mathrm{ATP}] /[\mathrm{ATP}+\mathrm{ADP}+\mathrm{AMP}]$, where ATP is adenosine triphosphate, ADP is adenosine diphosphate, and AMP is adenosine monophosphate.

Cytochemical determination of $\mathrm{Na}^{+}-\mathrm{K}^{+}$-adenosinetriphosphatase (ATPase) activity. Ventricular ouabain-sensitive $\mathrm{Na}^{+}-\mathrm{K}^{+}$-ATPase activity of sham-operated and thyroidectomized rats ( $n=7$ per group) was determined cytochemically by a technique adapted from Chayen and associates. ${ }^{22}$ Briefly, hearts were rapidly frozen in solid $\mathrm{CO}_{2}$ and $\mathrm{n}$-hexane and midventricular sections $(10 \mu \mathrm{m})$ flash-dried onto microscope slides (two sequential sections per slide). Total ATPase activity was determined by incubating one of the sections for 15 minutes with a Polypep low-viscosity medium (Sigma Chemicals, Poole, United Kingdom) of the following composition (in milligrams per milliliter): $\mathrm{NaCl} 24, \mathrm{MgCl}_{2} 4, \mathrm{KCl}$ 2.8 , adenosine triphosphate 10 , lead ammonium citrate acetate complex 32. Ouabain-insensitive $\mathrm{Na}^{+}-\mathrm{K}^{+}$-ATPase activity
Table I. Indices of in vivo cardiac pump function for sham-operated and thyroidectomized rats $(\mathrm{n}=8$ per group) 5 days after operation

\begin{tabular}{lcc}
\hline \multicolumn{1}{c}{ Index } & Sham-operated & Thyroidectomized \\
\hline HR (beats $/ \mathrm{min})$ & $418 \pm 10$ & $328 \pm 8^{*}$ \\
$\mathrm{MAP}(\mathrm{mm} \mathrm{Hg})$ & $112 \pm 4$ & $95 \pm 5^{*}$ \\
$\mathrm{RAP}(\mathrm{mm} \mathrm{Hg})$ & $3.6 \pm 0.3$ & $3.9 \pm 0.1$ \\
$\mathrm{CI}(\mathrm{ml} / \mathrm{min} / 100 \mathrm{gm}$ & $35 \pm 1$ & $22 \pm 2^{*}$ \\
$\quad$ body weight) & & \\
$\begin{array}{c}\mathrm{SVI}(\mu \mathrm{l} / \mathrm{beat} / 100 \mathrm{gm} \\
\quad \text { body weight) }\end{array}$ & $85 \pm 4$ & $67 \pm 7^{*}$ \\
$\begin{array}{c}\mathrm{SVRI}(\mathrm{mm} \mathrm{Hg} / \mathrm{ml} / \mathrm{min} / \\
\quad 100 \mathrm{gm} \text { body weight) }\end{array}$ & $3.1 \pm 0.2$ & $4.4 \pm 0.4^{*}$ \\
\hline
\end{tabular}

$H R$, heart rate; $M A P$, Mean arterial pressure; $R A P$, right atrial pressure; $C I$ cardiac index; $S V I$, stroke volume index; $S V R I$, systemic vascular resistance index. ${ }^{*} p<0.05$ when compared with the sham-operated group.

was assessed in the sequential section with an identical reaction medium supplemented with ouabain octahydrate $(1 \mathrm{mmol} / \mathrm{L})$. $\mathrm{Na}^{+}-\mathrm{K}^{+}$-ATPase activity was assumed to be equal to the difference between the total and ouabain-insensitive $\mathrm{Na}^{+}-\mathrm{K}^{+}$. ATPase activity. Sections were subsequently rinsed in Tris $(0.2$ $\mathrm{mmol} / \mathrm{L}, \mathrm{pH} 7.4$ at $37^{\circ} \mathrm{C}$ ) and then immersed in distilled water saturated with hydrogen sulfide. Finally, sections were mounted in a glycerol and water mixture $(2: 1)$ and the density of the lead sulfide reaction product quantified with a Vickers M85 microdensitometer (Vickers Systems, Ltd., Bedhampton, Hampshire, United Kingdom) at $585 \mathrm{~nm}$ and a flying spot of 0.5 mm diameter. Ten readings were taken from each of 10 cells per section. At least six sections were used for each heart. Ouabainsensitive $\mathrm{Na}^{+}-\mathrm{K}^{+}$-ATPase activity was expressed as mean integrated extinction $\times 100$.

Expression of results and statistical analysis. Coronary flow was expressed as milliliters per minute or as milliliters per minute per gram dry weight. CI was expressed as milliliters per minute per $100 \mathrm{gm}$ body weight, SVI as microliters per beat per $100 \mathrm{gm}$ body weight, and systemic vascular resistance index as millimeters of mercury per milliliter per minute per $100 \mathrm{gm}$ body weight. All results were expressed as means plus or minus the standard error of the mean. The unpaired, two-tailed Student's $t$ test was used for comparison between two means. A difference was considered statistically significant when $p<0.05$.

\section{Results}

All of the 46 rats that were entered into the study were included in the evaluation of results.

Effect of thyroidectomy on the plasma levels of thyroid hormones. Five days after operation the mean plasma concentrations of triiodothyronine and thyroxine in sham-operated animals were $1.90 \pm 0.08$ and 60.89 $2.60 \mathrm{nmol} / \mathrm{L}$, respectively. In thyroidectomized rats, these values fell to $0.65 \pm 0.04$ and $7.70 \pm 1.20 \mathrm{nmol} / \mathrm{L}$, respectively ( $p<0.05$ in each case).

Effects of thyroidectomy on the heart

Heart and body weight. Five days after operation the mean dry weight of hearts from thyroidectomized rats 

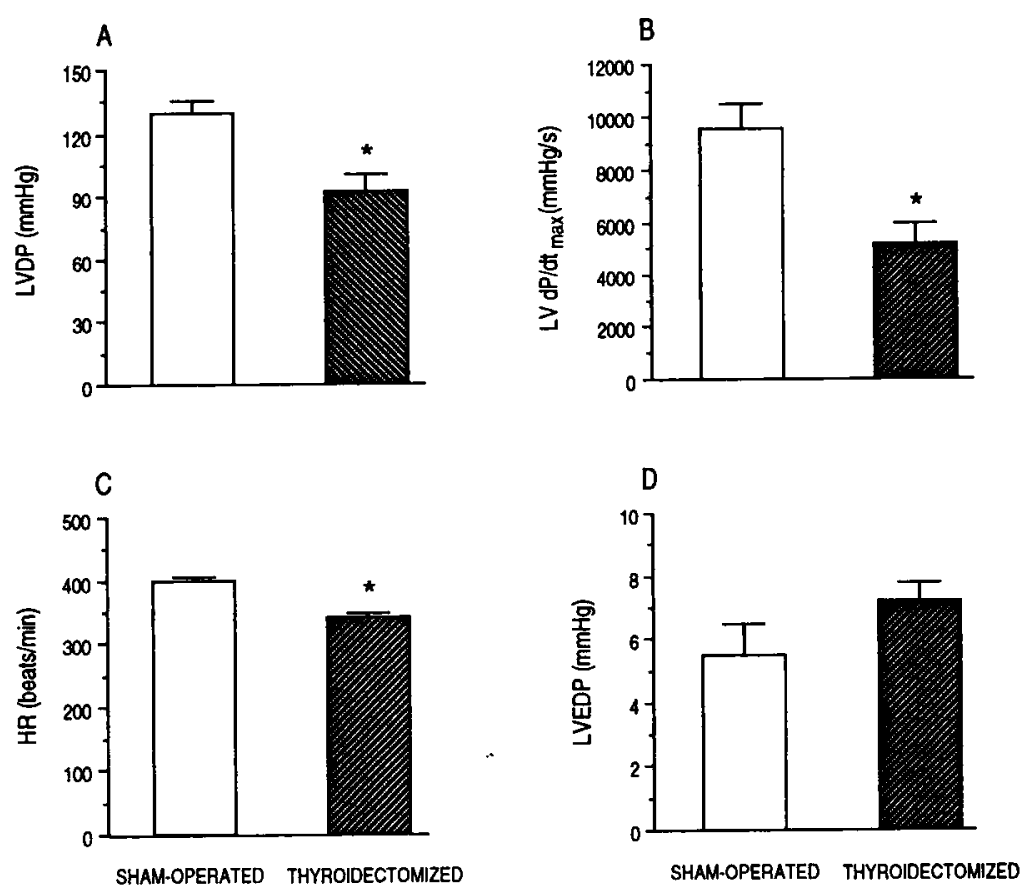

Fig. 1. Effect of thyroidectomy on (A) LVDP, (B) LV dP/dt $t_{\max }$, (C) heart rate $(H R)$, and (D) LVEDP 5 days after operation. Each column represents mean of eight measurements and bars represent standard error of mean. Asterisk indicates $p<0.05$ when compared with sham-operated group.
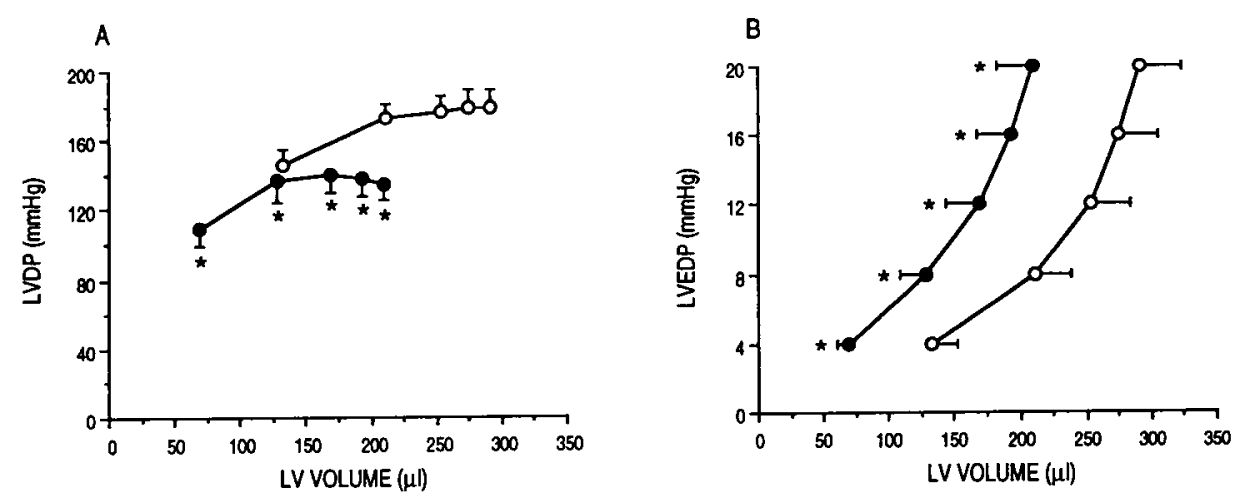

Fig. 2. Effect of thyroidectomy (solid circles) on (A) systolic and (B) diastolic cardiac function when assessed 5 days after operation in isolated blood-perfused heart. Each point represents mean of eight measurements and bars represent standard error of mean. $L V$, Left ventricular. Asterisk indicates $p<0.05$ when compared with sham-operated group (open circles).

was lower than that of hearts from the sham-operated animals $(213 \pm 5$ versus $238 \pm 5 \mathrm{mg}$, respectively; $p<0.05$ ). In addition, the mean increase in body weight of thyroidectomized rats $(19 \pm 3 \mathrm{gm})$ over 5 days was less than that observed in sham-operated control animals $(27 \pm 3 \mathrm{gm})$, however, this difference failed to achieve statistical significance. As a result, the heart dry weight/ body weight ratio did not differ significantly between thyroidectomized and sham-operated rats $(6.8 \pm 0.1$ versus $7.4 \pm 0.2$ ).

Cardiac pump function in vivo. The assessment of cardiac pump function by thermodilution (Table I) showed that the mean arterial pressure, CI, and SVI were significantly lower in the thyroidectomized rats than in the 
sham-operated control animals. This hemodynamic deterioration was not caused by differences in preload inasmuch as the right atrial pressure was similar in both groups. However, the heart rate was lower and the systemic vascular resistance index higher in thyroidectomized rats than in sham-operated rats and these differences may account, at least in part, for the observed decrease in the CI.

Cardiac contractile function in vivo. In another series of experiments, the in vivo assessment of cardiac function, using an intraventricular catheter, revealed significantly depressed function in thyroidectomized rats as compared with that in sham-operated animals (Fig. 1). The mean values for $L V D P$ and $L V ~ d P / d_{\max }$ were $129 \pm 6 \mathrm{~mm} \mathrm{Hg}$ and $9600 \pm 900 \mathrm{~mm} \mathrm{Hg} / \mathrm{sec}$ in the sham-operated control rats whereas in the thyroidectomized rats the corresponding values were $92 \pm 8 \mathrm{~mm} \mathrm{Hg}$ and $5190 \pm 790$ $\mathrm{mm} \mathrm{Hg} / \mathrm{sec}(p<0.05$ in each instance). Heart rate was again lower in thyroidectomized rats ( 340 beats $/ \mathrm{min}$ ) than in sham-operated rats $(398 \pm 6$ beats/min; $p<0.05)$. LVEDP was similar in both groups.

Cardiac function in vitro. The excision and ex vivo perfusion of the hearts for 40 minutes with blood from a support rat further confirmed the impaired contractile function of hearts from thyroidectomized rats (Fig. 2, $A$ ). Thus the mean LVDP (at an end-diastolic pressure of 8 $\mathrm{mm} \mathrm{Hg}$ ) was $136 \pm 12 \mathrm{~mm} \mathrm{Hg}$ in the thyroidectomized group whereas in the sham-operated group it was $173 \pm 8 \mathrm{~mm} \mathrm{Hg}(p<0.05)$. In addition, diastolic function (Fig. 2, B), as assessed by the slope of the relationship between increased left ventricular volumes and LVEDP, was impaired in the thyroidectomized group. Hearts from thyroidectomized rats also exhibited a decreased coronary flow $(1.8 \pm 0.1 \mathrm{ml} / \mathrm{min}$ versus $2.7 \pm 0.2 \mathrm{ml} / \mathrm{min}$ in the sham-operated group; $p<0.05$ ). The difference in coronary flow was also evident when the results were expressed on a dry weight basis $(8.6 \pm 0.7$ versus $11.4 \pm 0.7 \mathrm{ml} / \mathrm{min} / \mathrm{gm}$ dry weight, respectively; $p<0.05)$.

Tissue metabolites and myocardial energy status. Table II shows that 5 days after the removal of the thyroid gland, phosphocreatine, adenine nucleotide, and nicotinamide adenine dinucleotide contents and the adenylate energy charge of the myocardium were not significantly affected.

Tissue $\mathrm{Na}^{+}-\mathrm{K}^{+}$-ATPase activity. Five days after the removal of the thyroid, total ATPase activity of the myocardium was unchanged. However, as shown in Fig. 3 there was a significant depression of the $\mathrm{Na}^{+}-\mathrm{K}^{+}$-ATPase activity and a concomitant increase in the activity of the ouabain-insensitive fraction (which represents all cellular ATPase activity except that of $\mathrm{Na}^{+}-\mathrm{K}^{+}$-ATPase).

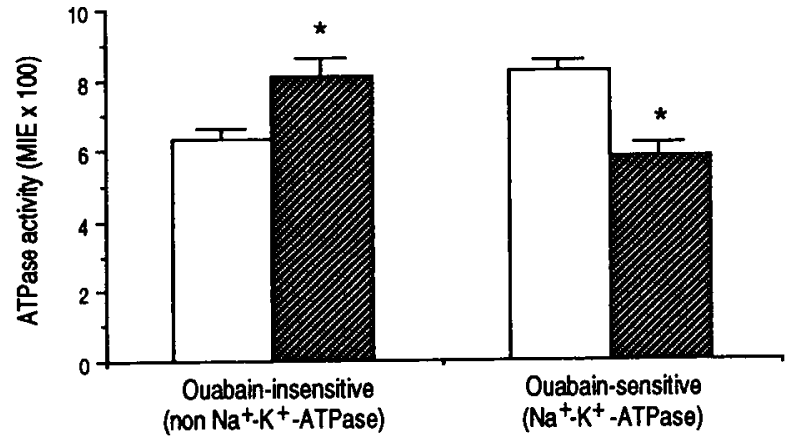

Fig. 3. Effect of thyroidectomy (hatched columns) on myocardial $\mathrm{Na}^{+}-\mathrm{K}^{+}$-ATPase activity when assessed 5 days after operation (total tissue ATPase activity can be derived by addition of ouabain-insensitive and ouabain-sensitive ATPase activity). Each column represents mean of seven hearts and bars represent standard error of mean. $M I E$, Mean integrated extinction. Asterisk indicates $p<0.05$ when compared with corresponding sham-operated group (open columns).

Effects of thyroidectomy on the tolerance of the heart to hypothermic ischemic storage

Ex vivo cardiac function. Fig. 4 shows the postischemic recovery of systolic and diastolic function in hearts from sham-operated and thyroidectomized rats. After 6 hours of hypothermic ischemia and 40 minutes of reperfusion, LVDP (at an end-diastolic pressure of $8 \mathrm{~mm} \mathrm{Hg}$ ) was significantly decreased in the sham-operated group $(131 \pm 8 \mathrm{~mm} \mathrm{Hg})$ when compared with that in the preischemic control rats $(173 \pm 8 \mathrm{~mm} \mathrm{Hg}$, see previous section). When compared with that in preischemic control rats, the postischemic LVDP in the thyroidectomized group exhibited a slight deterioration $(110 \pm 8$ versus $136 \pm 12 \mathrm{~mm} \mathrm{Hg}$; not significant), but in absolute terms these values did not differ significantly from the postischemic values in the sham-operated group (131 $\pm 8 \mathrm{~mm}$ $\mathrm{Hg}$ ). Diastolic function (Fig. 4, $B$ ) also recovered to the same extent in both groups. Postischemic coronary flow recovered equally in the sham-operated and thyroidectomized groups irrespective of whether flow was expressed as milliliters per minute $(3.1 \pm 0.3$ and $2.6 \pm 0.2$ $\mathrm{ml} / \mathrm{min}$, respectively; not significant) or as milliliters per minute per gram dry weight $(12.9 \pm 1.3$ and $12.4 \pm 0.9$ $\mathrm{ml} / \mathrm{min} / \mathrm{gm}$ dry weight, respectively; not significant).

Tissue metabolites and myocardial energy status. Table II shows the metabolite values at the end of the 40 minutes of reperfusion in the sham-operated and thyroidectomized groups. There was a slight but significant loss of adenosine triphosphate, adenosine diphosphate, and total adenylate pool in both groups when compared with preischemic values. The tissue content of phosphocreatine was increased in both groups. The adenylate energy 

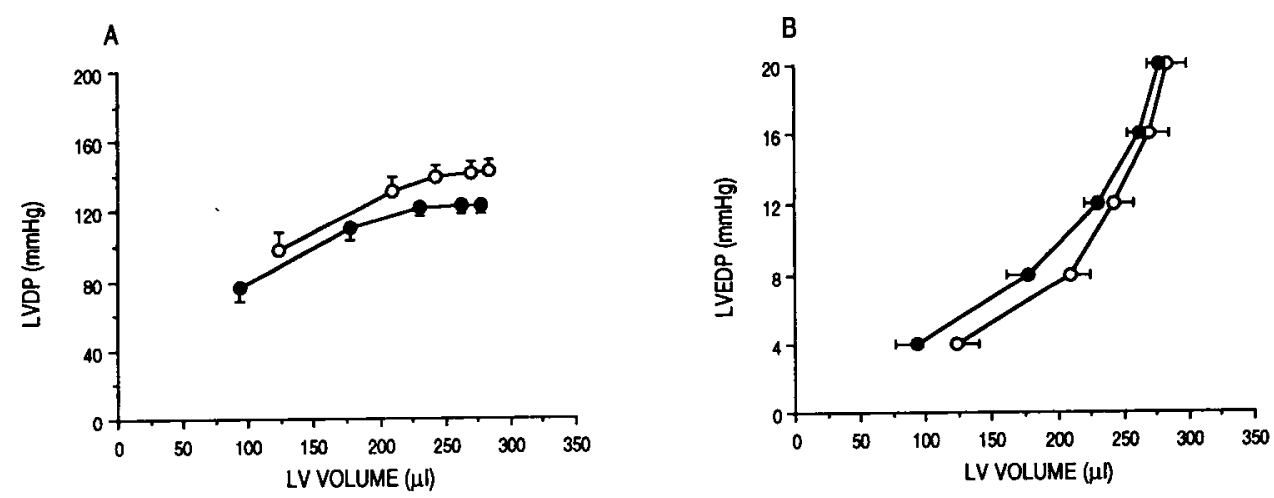

Fig. 4. Effect of thyroidectomy (solid circles) on postischemic recovery of $(\mathbf{A})$ systolic and $(\mathbf{B})$ diastolic cardiac function after 6 hours of hypothermic $\left(4^{\circ} \mathrm{C}\right)$ ischemia and 40 minutes of reperfusion $\left(37^{\circ} \mathrm{C}\right)$ in isolated blood-perfused heart. Each point represents mean of eight measurements and bars represent standard error of mean. $L V$, Left ventricular. Asterisk indicates $p<0.05$ when compared with sham-operated group (open circles).

Table II. Tissue metabolite content (in micromoles per gram dry weight) in hearts $(\mathrm{n}=8$ per group) from sham-operated and thyroidectomized rats aerobically perfused (isolated blood-perfusion preparation) for 40 minutes or subjected to 6 hours of hypothermic $\left(4^{\circ} \mathrm{C}\right)$ ischemia and 40 minutes of reperfusion

\begin{tabular}{lllllllc}
\hline \multicolumn{1}{c}{ Group } & \multicolumn{1}{c}{$P C r$} & \multicolumn{1}{c}{$A T P$} & \multicolumn{1}{c}{$A D P$} & \multicolumn{1}{c}{$A M P$} & \multicolumn{1}{c}{ TAN } & NAD & AEC \\
\hline Sham-operated (preischemic control) & $37.3 \pm 0.9$ & $18.8 \pm 0.9$ & $4.5 \pm 0.4$ & $0.79 \pm 0.19$ & $24.1 \pm 0.8$ & $2.62 \pm 0.15$ & $0.87 \pm 0.02$ \\
Sham-operated (postischemia) & $48.0 \pm 1.4^{*}$ & $16.2 \pm 0.2^{*}$ & $3.5 \pm 0.1^{*}$ & $0.43 \pm 0.04$ & $20.1 \pm 0.3^{*}$ & $2.92 \pm 0.11$ & $0.89 \pm 0.01$ \\
Thyroidectomized (preischemic control) & $43.2 \pm 1.3$ & $19.8 \pm 0.6$ & $4.5 \pm 0.1$ & $0.59 \pm 0.04$ & $24.9 \pm 0.7$ & $3.11 \pm 0.07$ & $0.89 \pm 0.01$ \\
Thyroidectomized (postischemia) & $50.6 \pm 1.9^{*}$ & $15.8 \pm 0.5^{*}$ & $3.4 \pm 0.1^{*}$ & $0.37 \pm 0.03^{*}$ & $19.5 \pm 0.6^{*}$ & $3.02 \pm 0.18$ & $0.90 \pm 0.01$ \\
\hline
\end{tabular}

PCr, Phosphocreatine; $A T P$, adenosine triphosphate; $A D P$, adenosine diphosphate; $A M P$, adenosine monophosphate; $T A N$, total adenylate pool; $N A D$, nicotinamide adenine dinucleotide; $A E C$, adenylate energy charge.

$*_{p}<0.05$ when compared with the corresponding group before ischemia.

charge recovered fully in both groups and nicotinamide adenine dinucleotide contents remained unchanged.

\section{Discussion}

The present study shows that hypothyroidism, induced by thyroidectomy, leads to a significant decrease in the plasma levels of triiodothyronine and thyroxine and an early deterioration of cardiac systolic and diastolic functions, irrespective of whether function is assessed in vivo or in vitro. These changes do not, however, impair the tolerance of the heart to extended periods of hypothermic ischemic storage, such as may be used during cardiac transplantation. A number of aspects of our study warrant further discussion.

Mechanisms for the early effects of hypothyroidism on the heart. A number of mechanisms may be responsible for the changes in cardiac function that occur after removal of the thyroid gland.

Calcium homeostasis. In many ways, the effects of thyroidectomy and hypothyroidism on systolic and diastolic cardiac functions are suggestive of changes in calcium handling. In this connection, Binah, Rubinstein, and
Gilat $^{23}$ have demonstrated a depression of inward calcium current in ventricular myocytes from hypothyroid guinea pigs. Seppet and associates ${ }^{17}$ have also shown depressed activities for calcium pumps in the sarcolemma and sarcoplasmic reticulum from hearts of hypothyroid rats. Furthermore, Arai and associates ${ }^{16}$ have demonstrated a decrease in messenger ribonucleic acid levels for the sarcoplasmic reticulum $\mathrm{Ca}^{2+}$-ATPase and calcium release channel (ryanodine receptor) proteins in myocardial tissue from hypothyroid rabbits. Hyperthyroidism appears to exert the opposite effect: in ferret papillary muscles and in myocytes from rats, it acts to accelerate the release and reuptake of calcium without altering peak cytosolic calcium levels. ${ }^{24,25}$ Hyperthyroidism has also been shown to increase the messenger ribonucleic acid and protein levels for sarcoplasmic reticulum $\mathrm{Ca}^{2+}$ ATPase and the calcium release channel. ${ }^{16,17}$ The early manifestation of systolic and diastolic functional changes after thyroidectomy, as observed in the present study, are supportive of changes in calcium homeostasis.

Activity of $\mathrm{Na}^{+}-\mathrm{K}^{+}$-ATPase. Another factor that may be involved in the thyroid control of cardiac contractility 
relates to changes in the activity of $\mathrm{Na}^{+}-\mathrm{K}^{+}$-ATPase. Various investigators have demonstrated that triiodothyronine is an important regulator of $\mathrm{Na}^{+}-\mathrm{K}^{+}$-ATPase in the heart and other mammalian tissues. ${ }^{17,26-29}$ In the present study, we observed that significant changes in $\mathrm{Na}^{+}-\mathrm{K}^{+}$-ATPase activity occur as soon as 5 days after the removal of the thyroid gland. Accordingly, it may well be that altered $\mathrm{Na}^{+}-\mathrm{K}^{+}$-ATPase activity influences calcium homeostasis by its effect on intracellular sodium and $\mathrm{Na}^{+}-\mathrm{Ca}^{2+}$ exchange. Arguing against this hypothesis is the observation that $\mathrm{Na}^{+}-\mathrm{Ca}^{2+}$ exchange activity is unaltered in the sarcolemmal preparations derived from hypothyroid rat hearts. ${ }^{17}$

Myosin ATPase. Thyroid hormones can also regulate the phenotypic expression of ventricular myosin ATPase isoforms, ${ }^{13,30-32}$ and this has been correlated with changes in myocardial contractility. ${ }^{13,33,34}$ However, the effect of hypothyroidism on the regulation of myosin ATPase is a slow process that may require more than 1 week to induce significant changes, ${ }^{30}$ a time longer than that used in the present study. Thus although we were unable to measure myosin ATPase activity it would seem unlikely that this plays a major role in the phenomena observed in the present study.

Myocardial energy status. Another possibility is that the depressed cardiac contractile function observed in hypothyroidism is caused by an alteration in energy production. ${ }^{35}$ However, our study, like others, ${ }^{11}$ shows that hypothyroidism has no effect on the myocardial content of high-energy phosphates and thus does not support the hypothesis that the myocardial energy status is involved in the deterioration of cardiac contractile function.

Reduction in coronary flow. Yet another possibility is that the low coronary flow observed in hearts from thyroidectomized rats may result in a reduction in cardiac stretch and hence in the length of the sarcomere, leading to a fall in tension development via the Frank-Starling mechanism. ${ }^{36}$ Nevertheless, it might also be possible that the reduced coronary flow is the result of a decreased energy requirement by a myocardium that is doing less work. The elucidation of this point would require, however, further investigation.

Effects of hypothyroidism on the tolerance of the heart to hypothermic ischemia. The present study shows that, although hypothyroidism depresses the preischemic function of hearts, it does not decrease their tolerance to long periods of hypothermic ischemic storage. As a consequence, the absolute value for the postischemic recovery of cardiac function after 6 hours of hypothermic ischemia was similar in both the sham-operated and thyroidectomized groups. When postischemic recovery was expressed as a percentage of preischemic function, the recovery was greater in the thyroidectomized group, possibly even suggesting an enhanced resistance to ischemic injury.

The better recovery of diastolic function after ischemia in the thyroidectomized group, when compared with its preischemic values, would further support the concept that hearts from hypothyroid rats may possess a greater tolerance to ischemic injury. The argument that this better recovery could have been a result of reperfusion with blood from an euthyroid rat cannot be sustained, because function of hearts from thyroidectomized rats that were not subjected to ischemia remained impaired despite their perfusion with blood from euthyroid rats for the same period of time.

The factors responsible for this relative resistance of the heart to hypothermic ischemia in thyroidectomized rats is unknown. Because ischemia disturbs the control of calcium regulation by the myocyte ${ }^{37,38}$ (and this would impair the ability of the heart to recover ${ }^{39}$ ), one might speculate that changes in calcium homeostasis, as seen in hypothyroidism, may modify the response of the heart to an ischemic insult. Indeed, any of the many cellular changes induced by hypothyroidism might be expected to participate in the complex pathophysiologic events that occur during ischemia and reperfusion.

Clinical implications. It has been suggested that administration of thyroid hormones to brain-dead patients can improve their hemodynamic status and that this may result in a better clinical outcome for transplant recipients. ${ }^{7}$ However, if the processes in man behave like those in the rat and if the deficit of thyroid hormones does not reduce the tolerance of the heart to hypothermic ischemia, the question then arises as to whether therapeutic supplementation with these hormones is necessary. Further studies are clearly warranted.

Concluding comments. We conclude that hypothyroidism induced by thyroidectomy leads to an early ( 5 days) deterioration of systolic and diastolic cardiac functions. For the rat heart, at least, these functional alterations do not decrease its tolerance to a long period of hypothermic ischemic storage.

We thank Drs. C. Saldanha and G. Brooks for their valuable discussion. We also thank Dr. A. K. Sinha for the determination of plasma levels of thyroid hormones.

\section{REFERENCES}

1. Robertson KM, Hramiak IM, Gelb AW. Endocrine changes and hemodynamic stability after brain death. Transplant Proc 1989;21:1197-8.

2. Powner DJ, Hendrich A, Lagler RG, Ng RH, Madden RL. Hormonal changes in brain dead patients. Crit Care Med 1990;18:702-8. 
3. Novitzky D, Wicomb WN, Cooper DKC, Rose AG, Fraser RC, Barnard CN. Electrocardiographic, hemodynamic and endocrine changes occurring during experimental brain death in the chacma baboon. J Heart Transplant 1984;4: 63-9.

4. Gifford RR, Weaver AS, Burg JE, Romano PJ, Demers LM, Pennock JL. Thyroid hormone levels in heart and kidney cadaver donors. J Heart Transplant 1986;5:249-53.

5. Howlett TA, Keogh AM, Perry L, Touzel R, Rees LH. Anterior and posterior pituitary function in brain-stemdead donors: a possible role for hormonal replacement therapy. Transplantation 1989;47:828-34.

6. Taniguchi S, Kitamura S, Kawachi K, Aoyama N. Effects of hormonal supplements on the maintenance of cardiac function in potential donor patients after cerebral death. Eur J Cardiothorac Surg 1992;6:96-102.

7. Novitzky D, Cooper DKC, Reichart B. Hemodynamic and metabolic responses to hormonal therapy in brain-dead potential organ donors. Transplantation 1987;43:852-4.

8. Oppenheimer JH. The nuclear receptor-triiodothyronine complex: relationship to thyroid hormone distribution, metabolism, and biological action. In: Oppenheimer JH, Samuels HH, eds. Molecular basis of thyroid hormone action. New York: Academic Press, 1983:1-35.

9. Theilen EO, Wilson WR. Hemodynamic effects of peripheral vasoconstriction in normal and thyrotoxic subjects. $\mathrm{J}$ Appl Physiol 1967;22:207-10.

10. Howitt G, Rowlands DJ. The heart in hyperthyroidism. Am Heart J 1967;73:282-3.

11. Buccino RA, Spann JF, Pool PE, Sonnenblick EH, Braunwald $\mathrm{E}$. Influence of the thyroid state on the intrinsic contractile properties and energy stores of the myocardium. $\mathbf{J}$ Clin Invest 1967;10:1669-82.

12. Wheeldon D, Sharples L, Wallwork J, English T. Donor heart preservation survey. J Heart Lung Transplant 1992; 11:986-93.

13. Rovetto MJ, Hjalmarson AC, Morgan HE, Barrett MJ, Goldstein RA. Hormonal control of cardiac myosin adenosine triphosphate. Circ Res 1972;31:397-409.

14. Brooks I, Flynn SB, Owen AA, Underwood AH. Changes in cardiac function following administration of thyroid hormones in thyroidectomized rats: assessment using the isolated working rat heart preparation. J Cardiovasc Pharmacol 1985;7:290-6.

15. Dieckman LJ, Solaro RJ. Effect of thyroid status on thinfilament $\mathrm{Ca}^{2+}$ regulation and expression of troponin $\mathrm{I}$ in perinatal and adult rat hearts. Circ Res 1990;67:344-51.

16. Arai M, Otsu K, MacLennan DH, Alpert NR, Periasamy $M$. Effect of thyroid hormone on the expression of mRNA encoding sarcoplasmic reticulum proteins. Circ Res 1991;69:266-76.

17. Seppet EK, Kadaya LY, Hata T, et al. Thyroid control over membrane processes in rat heart. Am J Physiol 1991; 26(suppl):66-71.

18. Galiñanes $M$, Hearse DJ. Brain death-induced impairment of cardiac contractile performance can be reversed by explanation and may not preclude the use of hearts for transplantation. Circ Res 1992;71:1213-9.

19. Ekins RP. Radio assay methods. In: Radiopharmaceuticals: II. Proceedings of the Second International Symposium on Pharmaceuticals. Seattle, Washington, 1979:21940.

20. Langendorff $O$. Untersuchungen am uberlebenden Saugetierherzen. Pflugers Arch 1895;61;219-332.

21. Smolenski RT, Lachno DR, Ledingham SJM, Yacoub MH. Determination of sixteen nucleotides, nucleosides and bases using high-performance liquid chromatography and its application to the study of purine metabolism in hearts for transplantation. J Chromatogr 1990;527:414 20.

22. Chayen J, Frost GTB, Dodds RA, et al. The use of a hidden metal-capture reagent for the measurement of Na-KATPase activity: a new concept in cytochemistry. Histochemistry 1981;71:533-41.

23. Binah O, Rubinstein I, Gilat E. Effects of thyroid hormone on the action potential and membrane currents of guinea pig ventricular myocytes. Pflugers Arch 1987;409:214-6.

24. MacKinnon R, Morgan JP. Influence of the thyroid state on the calcium transient in ventricular muscle. Pflugers Arch 1986;407:142-4.

25. Beekman RE, van Hardeveld C, Simonides WS. Effect of thyroid state on cytosolic free calcium in resting and electrically stimulated cardiac myocytes. Biochim Biophys Acta 1988;969:18-27.

26. Ng YC, Yao AZ, Akera T. Tissue-specific isoform regulation of $\mathrm{Na}^{+}-\mathrm{K}^{+}$-ATPase by thyroid hormone in ferrets. Am J Physiol 1989;257:H534-9.

27. Curfman GD, Crowley TJ, Smith TW. Thyroid induced alterations in myocardial sodium-activated adenosine triphosphate, monovalent cation active transport, and cardiac glycoside binding. J Clin Invest 1977;59:586-90.

28. Lin $\mathrm{MH}$, Akera T. Increased $\left(\mathrm{Na}^{+}-\mathrm{K}^{+}\right)$-ATPase concentrations in various tissues of rats caused by thyroid hormone treatment. J Biol Chem 1978;253:723-6.

29. Gick GG, Ismail-Beigi $F$. Thyroid hormone induction of $\mathrm{Na}^{+}-\mathrm{K}^{+}$-ATPase and its mRNAs in a rat liver cell line. Am J Physiol 1990;258:C544-51.

30. Hoh JFY, McGrath PA, Hale PT. Electrophoretic analysis of multiple forms of rat cardiac myosin: effects of hypophysectomy and thyroxine replacement. J Mol Cell Cardiol 1977;10:1053-76.

31. Lompre AM, Nadal-Ginard B, Mahdavi V. Expression of the cardiac ventricle $\alpha$ - and $\beta$-myosin heavy chain genes is developmentally and hormonally regulated. J Biol Chem 1984;259:6437-46.

32. Martin AF, Pagani ED, Solaro RJ. Thyroxine-induced redistribution of isoenzymes of rabbit ventricular myosin. Circ Res 1982;50:117-24.

33. Goodkind MJ, Dambach GE, Thyrum PT, Luchi RJ. Effect of thyroxine on ventricular myocardial contractility and ATPase activity in guinea pigs. Am J Physiol 1974; 226:66-72. 
34. Schwartz K, Lecarpentier Y, Martin JL, Lompre AM, Mercadier JJ, Swynghedauw B. Myosin isoenzymic distribution correlates with speed of myocardial contraction. J Mol Cell Cardiol 1981;13:1071-5.

35. Nishiki K, Erecinska M, Wilson DF, Cooper S. Evaluation of oxidative phosphorylation in hearts from euthyroid, hypothyroid and hyperthyroid rats. Am J Physiol 1978; 235:C212-9.

36. Arnold G, Kosche F, Miessner E, Neitzert A, Lochner W. The importance of the perfusion pressure in the coronary arteries for the contractility and the oxygen consumption of the heart. Pflugers Arch 1968;299:339-56.
37. Steenbergen C, Murphy E, Levy L, London RE. Elevation in cytosolic free calcium concentration early in myocardial ischemia in perfused rat heart. Circ Res 1987;60:7007.

38. Knopf H, Theising R, Moon CH, Hirche HJ. Continuous determination of extracellular space and changes of $\mathrm{K}^{+}$, $\mathrm{Na}^{+}, \mathrm{Ca}^{2+}$, and $\mathrm{H}^{+}$during global ischaemia in isolated rat hearts. J Mol Cell Cardiol 1990;22:1259-72.

39. Nayler WG, Perry S, Elz JS, Daly MJ. Calcium, sodium and the calcium paradox. Circ Res 1984;55:227-37. 